\title{
Para uma interpretação do conceito de Bildungsroman
}

Flavio Quintale Neto*

\begin{abstract}
This article suggests a possible meaning of the concept of Bildungsroman. It analyzes Goethe's Wilhelm Meister Lehrjahre, a novel that is considered the model of this kind of narrative and argues that Goethe shows how the union of action and contemplation is an ideal required to create a balanced humanist man. It also discusses Novalis' Heinrich von Ofterdingen as an anti-model to Goethe.
\end{abstract}

Keywords: Bildungsroman; Goethe; Humanism; Praxis and Contemplation

Zusammenfassung: Dieser Artikel unternimmt den Versuch, die Bedeutung des Begriffes „Bildungsroman“ zu verstehen. Er gibt zunächst Kommentare zu Goethes Wilhelm Meisters Lehrjahre, dem Roman, der als Modell für alle anderen Bildungsromane fungierte. Es wird die Hypothese aufgestellt, dass es Goethe um eine Verbindung von Tat und Kontemplation ging. Im Anschluss wird Novalis' Roman Heinrich von Ofterdingen im Hinblick auf das Bildungskonzept betrachtet.

Stichwörter: Bildungsroman; Goethe; Humanismus; Praxis und Kontemplation

O autor é doutorando em Teoria Literária e Literatura Comparada pela USP e professor dos cursos de Letras e Filosofia da Universidade Metodista de São Paulo. 
Resumo: Neste artigo tenta-se compreender o sentido do chamado Romance de Formação. É feita uma curta analise do romance Os anos de aprendizado de Wilhelm Meister de Goethe, obra modelo desse gênero narrativo. Argumentase que Goethe propõe, como ideal de busca para a formação do homem Humanista, a união entre a práxis e a contemplação. Discute-se também o Romance de Formação antimodelo: Henrique de Ofterdingen de Novalis.

Palavras-chave: Romance de formação; Goethe; humanismo; práxis e contemplação

\section{1. $O$ conceito do Bildungsroman}

Sugere-se, neste artigo, que Bildungsroman é um tipo de romance que se caracteriza pela formação do protagonista e do leitor nos princípios do humanismo, produzindo uma tentativa de síntese entre práxis e contemplação.

Contudo, ao se estudar o conceito Bildungsroman, traduzido usualmente como "Romance de Formação", a primeira questão que se coloca é: o que de fato é um Bildungsroman? A resposta não é fácil e às vezes mesmo nos frustra não encontrar uma explicação completa e convincente do que vem a ser um Bildungsroman.

Como afirma Rolf Selbmann,"pode-se traduzir o conceito Bildung, mas a palavra é intraduzivel”. (SELBMANN 1994: 1)1 Embora o conceito de Bildung seja intraduzível, em português convencionou-se chamar Bildungsroman de Romance de Formação, que, não obstante próximo, não tem o mesmo sentido. Antes de se delimitar um possível conceito para o Bildunsroman, é necessário entender o sentido de Bildung. A origem do termo é medieval, usada por Mestre Eckhart, e tem, portanto, estreita relação religiosa. Rolf Selbmann explica que "Bildung (alto-alemão arcaico. Bildunga, alto-alemão médio. Bildunge) circunscrevia primeiramente uma aura de valor, significava a Foto, o Retrato, a Imagem (imago), mas também Imitação (imitatio), Forma (forma) und Formação (formatio). Ainda o modelo da imagem da divindade, cujo centro, é ocupado pelo homem. Posteriormente, entre os místicos do

1 "Der Begriff Bildung ist ein unübersetzbares Wort, die Sache nicht." 
final da Idade Média, a Bildung tornou-se o conceito chave da teoria ImagoDei do círculo de Mestre Eckhart. Quando seu significado se altera para "transformatio", aponta para o conceito de reconquista do paraíso perdido, significando também a remodelação do pecado original do homem culpado como "superimagem", novo portador da imagem divina". (Selbmann 1994: 1)².

Em outras palavras, a origem do conceito de Bildung remete a concepção do homem como imagem da divindade. Contudo, ao cometer o pecado original, o homem perdeu essa imagem divina original e só pode reconquistá-la transformando-se a si mesmo. Busca-se essa transformação através da reconquista daquela imagem original perdida, que tornaria possível, assim, a reconciliação do homem com a divindade. Os críticos alemães Jürgen Jacobs e Markus Krause procuram sintetizar as características fundamentais que tornam um romance um típico Bildungsroman:

O protagonista deve ter uma consciência de certa forma explícita de que ele próprio não percorre uma seqüência de aventuras mais ou menos aleatórias, mas sim um processo de autodescobrimento e de orientação no mundo. Com isso, via de regra, a imagem que o protagonista tem da meta de sua trajetória de vida é determinada por enganos e avaliações equivocadas, devendo ser corrigidas apenas no transcorrer de seu desenvolvimento. Ele tem como experiências típicas: o abandono da casa paterna, a atuação de mentores e de instituições acadêmicas, o encontro com a esfera da arte, confissões intelectuais eróticas, experiência profissional e também, eventualmente, contato com a vida política. Na plasmação e na valorização desses

2 "Bildung (ahd.bildunga, mhd.bildunge) umschrieb ursprünglich eine Wertaura, die Bild, Abbild und Ebenbild (imago) bedeutete, aber auch Nacbbildung (imitatio), Gestalt (forma) und Gestaltung (formatio). Immer stand eine vorbildhaft gemeinte Gottesbildlichkeit, nach der der Mensch ausgeprägt werden sollte, im Zentrum. Im Rahmen der spätmittelalterlichen Mystik wurde Bildung zum Schlüsselbegriff einer Imago-Dei-Theorie im Umkreis Meister Eckharts. In seiner leicht abgewandelten Bedeutung als transformatio zielte der Begriff auf die Wiedergewinnung des verlorenen paradiesischen Unschuldzustands, meinte also sowohl Umgestaltung des mit der Erbsünde belasteten Menschen als auch Überbildung, Neueinprägung des göttlichen Bildes.” 
motivos, os romances diferem extraordinariamente. Contudo, através da orientação para um final harmonioso, eles recebem necessariamente uma estrutura teleológica. (JACOBS \& KRAUSE 1989: 37) ${ }^{3}$

Essas características, essas aventuras com caminhos e descaminhos, aparecem como base de investigação para se compreender como Goethe construiu o seu Bildungsroman, Wilhelm Meisters Lehrjahre. Romance, este, de uma alma em luta com conflitos existenciais, como James Joyce faz o bibliotecário Lyster de Ulysses dizer: “Temos, não temos, aquelas preciosas páginas de Wilhelm Meister? Um grande poeta num grande poeta irmão. Uma alma hesitante tomando as armas contra um mar de problemas, dilacerada por dúvidas conflitantes, como se vê na vida real". (Joyce 1992: 235) ${ }^{4}$ Tomando como referência esse romance de Goethe, atesta Georg Lukács que

aqui se busca também um caminho intermediário entre o exclusivo orientar-se pela ação do idealismo abstrato e a ação puramente interna, feita contemplação, do Romantismo. A humanidade, como escopo fundamental desse tipo de configuração, requer um equilíbrio entre atividade e contemplação, entre vontade de intervir no mundo e a capacidade receptiva em relação a ele. Chamou-se essa forma de romance de educação. (LuKács 2000: 141).

3 "Dass sein Protagonist ein mehr oder weniger explizites Bewusstsein davon hat, nicht bloss eine beliebige Folge von Abenteuern, sondern einen Prozess der Selbstfindung und der Orientierung in der Welt zu durchlaufen. Dabei gilt in aller Regel, dass die Vorstellungen des Helden über das Ziel seines Lebensganges zunächst von Irrtümern und Fehleinschätzungen bestimmt sind und sich erst im Fortgang seiner Entwicklung korrigieren. Typische Erfahrungen der Bildungshelden sind die Auseinandersetzung mit dem Elterhaus, die Einwirkung von Mentoren und Erziehungsinstitutionen, die Begegnung mit der Sphäre der Kunst, erotische Seelenabenteuer, die Selbsterprobung in einem Beruf und bisweilen auch der Kontakt zum öffentlichpolitischen Leben. In der Gestaltung und Wertung dieser Motive differieren die verschiedenen Romane ausserordentlich. Durch die Orientierung auf ein harmonisches Ende bekommen sie indessen notwendig eine teleologische Struktur."

4 "And we have, have we not, those priceless pages of Wilhelm Meister? A great poet on a great brother poet. A hesitating soul taking arms against a sea of troubles, torn by conflicting doubts, as one sees in real life." 
Essa fusão entre contemplação e ação como ideal para a formação humanista da sociedade é essencial para a constituição do Romance de Formação ou Educação goethiano. O sentido que Bildungsroman tem em Goethe, autor do romance modelo deste gênero (ou sub-gênero) literário, Wilhelm Meisters Lehrjahre, pode ser entendido quando o protagonista Wilhelm enuncia :

Instruir-me a mim mesmo, tal como sou, tem sido obscuramente meu desejo e minha intenção, desde a infância. Ainda conservo essa disposição, com a diferença de que agora vislumbro com mais clareza os meios que me permitirão realizá-la. Tenho visto mais mundo que tu crês, e dele me tenho servido melhor que tu imaginas. Atente, portanto, àquilo que digo, ainda que não vá ao encontro de tuas opiniões. (GOETHE 1988: 289)

Instruir-se a si mesmo, “auto-formar-se”, sich auszubilden, é o que busca Wilhelm. Entretanto, dentro de uma outra perspectiva, inserido no próprio romance, é bastante curioso notar a inclusão no capítulo VI da Bekenntnisse einer schönen Seele (Confissões de uma bela alma), em que todo o processo de formação da "bela alma feminina" é de tendência pietista. Do ponto vista doutrinário, para o pietismo a salvação é conseguida através da fé particular em Deus e de uma vida individual de prática piedosa. Não há necessidade de se comprometer a certos dogmas e observâncias formais, pois a verdadeira igreja é a comunidade invisível de todos os crentes e não um prédio de pedra e tijolo. $O$ verdadeiro conhecimento vem diretamente de Deus e não é aprendido através de nenhum livro.

Dessa forma, o fato da formação da Bela Alma ser pietista é de suma importância para a compreensão do que constitui essa Bildung, já que o conhecimento de Deus é particular e místico. Nas "Confissões”, a formação

5 Todas traduções desse romance são de Nicolino S. Neto. "Dass ich Dir's mit einem Worte sage: mich selbst, ganz wie ich da bin, auszubilden, das war dunkel von Jugend auf mein Wunsch und meine Absicht. Noch hege ich eben diese Gesinnungen, nur dass mir die Mittel, die mir es möglich machen werden, etwas deutlicher sind. Ich habe mehr Welt gesehen, als Du glaubst, und sie besser benutzt, als Du denkst. Schenke deswegen dem, was ich sage, einige Aufmerksamkeit, wenn es gleich nicht ganz nach Deinem Sinne sein sollte." 
da bela alma se dá pelo seu desenvolvimento na experiência com a divindade através da sensibilidade, do coração, da religião particular, individual, longe de igrejas institucionalizadas. O conhecimento da divindade é por experiência pessoal, mística, pelo desabrochar do divino imanente. Relata a Bela Alma:

Como eu era feliz ao ver que milhares de pequenos acontecimentos reunidos me demonstravam, tanto quanto a respiração a comprovar o sinal de minha vida, que eu não estava sem Deus no mundo! Ele estava perto de mim, eu estava diante dele. $\mathrm{E}$ isso o que posso dizer com a máxima veracidade, evitando intencionalmente toda linguagem teológica sistemática. Quanto houvera desejado ver-me também totalmente livre de sistema; mas, quem alcança com rapidez a ventura de ser consciente de seu próprio eu, sem fórmulas estranhas, num puro encadeamento? Eu levava a sério meu fervor. (GoETHE 1988: 390) ${ }^{6}$

E ainda:

$\mathrm{Na}$ intimidade com meu amigo invisível, eu sentia o mais doce gozo de todas as minhas forças vitais. O desejo de continuar gozando de tal ventura era tão grande que de bom grado omitia aquilo que perturbava essa intimidade, e nisso a experiência era meu melhor mestre. (GoETHE 1988: 394)

Essa experiência da divindade interior levaria, por um impulso, ao encontro místico com Cristo e o conhecimento esotérico intrínseco da fé:

6 "Wie glücklich war ich, dass tausend kleine Vorgänge zusammen, so gewiss als das Atemholen Zeichen meines Lebens ist, mir bewiesen, dass ich nicht ohne Gott auf der Welt sei! Er war mir nahe, ich war vor ihm. Das ist's, was ich mit geflissentlicher Vermeidung aller theologischen Systemsprache mit grösster Wahrheit sagen kann. Wie sehr wünschte ich, dass ich mich auch damals ganz ohne System befunden hätte; aber wer kommt früh zu dem Glücke, sich seines eignen Selbsts, ohne fremde Formen, in reinem Zusammenhang bewusst zu sein? Mir war es Ernst mit meiner Seligkeit."

7 "In dem Umgange mit dem unsichtbaren Freunde fühlte ich den süssesten Genuss aller meine Lebenskräfte. Das Verlangen, dieses Glück immer zu geniessen, war so gross, dass ich gern unterliess, was diesen Umgang störte, und hierin war die Erfahrung mein bester Lehrmeister." 
Um impulso transportava minha alma para a cruz onde Jesus um dia morreu: um impulso, não posso chamá-lo de outro modo, em tudo semelhante àquele que conduz nossa alma para junto de um amado ausente, um aproximar-se, provavelmente muito mais essencial e verdadeiro do que suposmo. Assim se aproximava minha alma Daquele que se fez homem e que morreu na cruz, e nesse instante, eu soube o que era a fé. "Isto é a fé!", disse e dei um salto, como que meio assustada. (GoETHE 1988: 394$)^{8}$

As instruções que a Bela Alma recebe de seu tio são de grande valia para o aprofundamento de sua fé pietista, sobretudo no que concerne à identificação do homem como imagem imanente da divindade. Ensina o tio:

Não pode haver, pois, contradição entre o conceito de homem e o conceito de divindade, e se sentirmos com freqüência certa dessemelhança e afastamento dele, é, contudo, tanto mais nosso dever de não ver sempre em tudo, como o advogado do diabo, somente os pontos fracos e as debilidades de nossa natureza, mas sim procurar antes todas as perfeições, pelas quais podemos confirmar as pretensões de nossa semelhança divina. [...] Todo o ser do Universo estende-se diante de nós como uma grande pedreira diante do arquiteto, que só merece esse nome quando, dessa fortuita massa natural, compõe com máxima economia, adequação e solidez a imagem primitivamente concebida por seu espírito. Tudo o que está fora de nós não é senão um elemento, e poderia até mesmo dizer, também o que está em nós; mas no fundo de nós mesmos reside essa força criadora que nos permite criar o que deve ser e que não nos deixa descansar nem repousar

8 "Ein Zug brachte meine Seele nach dem Kreuze hin, an dem Jesus einst erblasste; ein Zug war es, ich kann es nicht anders nennen, demjenigen völlig gleich, wodurch unsre Seele zu einem abwesenden Geliebten geführt wird, ein Zunahen, das vermutlich viel wesentlicher und wahrhafter ist, als wir vermuten. So nahte meine Seele dem Menschgewordnen und am Kreuz Gestorbenen, und in dem Augenblicke wusste ich, was Glauben war. Das ist Glauben! Sagte ich und sprang wie halb erschreckt in die Höhe." 
até que tenhamos representado, de uma forma ou de outra, o que está fora ou dentro de nós. (Goethe 1988: 404)9

Além dessa identificação da divindade com o homem, há o uso de termos semelhantes aos usados pela maçonaria como Baumeister, Arquiteto, para Deus, e o mundo como uma pedreira, Steinbruch. Pela formação da Bela Alma vê-se que a Bildung pietista aproxima-se muito do conceito gnóstico já presente, como vimos, em Meister Eckhart. Diz a Bela Alma: "mas jamais me ocorreu pensar o quanto dependia de mim que minha alma estivesse igualmente formada, que ela parecesse um espelho no qual se poderia refletir o sol eterno, pois isso era algo que já havia definitivamente presumido". (Goethe 1988: 361) $)^{10}$

Há de se acrescentar, ainda, o fato de essa formação associada à experiência mística feminina (a bela alma) remontar ao cabalista cristão Jacob Boehme, cuja doutrina influenciou o pietismo, uma vez que para os pietistas a mulher está mais propícia ao contato com a divindade, pois em Deus haveria o "princípio feminino", a Shekina dos cabalistas. Como diz Paola Mayer: "Sofia ou sabedoria divina é o elemento passivo, feminino da

9 "Es muss also in dem Begriff des Menschen kein Widerspruch mit dem Begriff der Gottheit liegen, und wenn wir auch oft eine gewisse Unähnlichkeit und Entfernung von ihr empfinden, so ist es doch um desto mehr unsere Schuldigkeit, nicht immer wie der Advokat des bösen Geistes nur auf die Blössen und Schwächen unserer Natur zu sehen, sondern eher alle Vollkommenheiten aufzusuchen, wodurch wir die Ansprüche unsrer Gottähnlichkeit bestätigen können. [...] Das ganze Weltwesen liegt vor uns wie ein grosser Steinbruch vor dem Baumeister, der nur dann den Namen verdient, wenn er aus diesen zufällig Naturmassen ein in seinem Geiste entsprungenes Urbild mit der grössten Ökonomie, Zweckmässigkeit und Festigkeit zusammenstellt. Alles ausser uns ist nur Element, ja, ich darf wohl sagen, auch alles an uns; aber tief in uns liegt diese schöpferische Kraft, die das zu erschaffen vermag, was sein soll, und uns nicht ruhen und rasten lässt, bis wir es ausser uns oder an uns auf eine oder die andere Weise dargestellt haben."

10 "[...] aber nie fiel es mir ein, zu denken, wie es denn mit mir stehe, ob meine Seele auch so gestaltet sei, ob sie einem Spiegel gleich, von dem die ewige Sonne wiederglänzen könnte; das hatte ich ein für allemal schon vorausgesetzt.” 
divindade, o espelho no qual a vontade eterna (o Pai) vê a si mesmo e no qual projeta as imagens de todas coisas possíveis. No mundo criado, ela é o elemento divino na alma humana, a noiva celestial que Adão perdeu em sua queda." (MAYER 1999: 22) ${ }^{11}$

Goethe conhecia todas essas doutrinas. Em Dichtung und Wabrheit (Poesia e Verdade), parte II, livro 8, reconhece a grande influência que o livro Kirchenund Ketzerbistorie (História da Igreja e das Heresias) do pietista Gottfried Arnold (1666-1714) exerceu em suas idéias. Nesse livro, há a exposição das doutrinas de diversos místicos de orientação neoplatônica, gnóstica e cabalista, como Jacob Boehme, entre outros, que são a base da formação seguida pela Bela Alma, um formação de caráter contemplativo e místico.

Em oposição à formação mística da Bela Alma, apresenta-se um outro tipo de Bildung, que irá moldar o desenvolvimento do protagonista Wilhelm Meister. Ele é o artista errante que peregrina pelo mundo em busca de uma formação plena. O aprendizado de Wilhelm acontece por meio do contato com o mundo e com a natureza, mas sobretudo pela instrução da Gesellschaft vom Turm, uma sociedade secreta, um tipo de maçonaria. Wilhelm é instruído na busca do conhecimento de si mesmo consoante preceitos não exclusivamente místicos, como o da Bela Alma, mas através da peregrinação de sua alma nas artes, nas ciências, na natureza, na vida em sociedade. Dessa maneira, Wilhelm Meister pode ser lido não exclusivamente como um Romance de Formação, em sentido amplo, e sim como Romance de Formação Humanista. Como comenta Georg Lukács:

A realização dos ideais humanistas é neste romance não só o parâmetro para julgar as diversas classes e seus representantes, como também a força propulsora e o critério da ação de todo romance. Em Wilhelm Meister e em muitas outras personagens desta obra, a realização dos ideais humanistas em suas vidas é a mola propulsora mais ou menos consciente de suas ações. [...] O traço peculiar do romance goethiano mostra-se contudo no fato de que, por um lado, essa visão de mundo

11 "Sophia or divine wisdom is the feminine, passive element of the divinity, the mirror in which the eternal will (the Father) sees itself and in which it projects the images of all possible things. In the created world, she is the divine element in the human soul, the heavenly bride whom Adam lost by his fall." 
(humanista) se põe no centro de tudo com uma elevada consciência, acentuada permanentemente de modo filosófico, ou pelo estado de ânimo, ou relacionada com a ação, a ponto de se transformar na força motriz consciente de todo o mundo configurado; e, por outro lado, essa peculiaridade consiste em que Goethe nos apresente como um devir real de seres humanos concretos em circunstâncias concretas essa realização da personalidade plenamente desenvolvida com que o Renascimento e o Iluminismo sonharam, e que na sociedade burguesa tem sempre permanecido como utopia. (LUKÁCs 1994: 598)

As relações entre humanismo, pietismo, maçonaria e Bildungsroman são deveras estreitas, como lembra Anna Giubertoni:

Bem longe de assumir uma posição anti-religiosa, a maçonaria alemã insere-se na corrente da tradição mística e está pronta a fazer confluir em si a aura de intensa participação da célula pietista com os ideais iluministas da tolerância e da Humanidade. O ponto de maior contato íntimo e a herança direta que os maçons trazem dos pietistas é justamente o Bildungsideal, que se preocupa agora com um valor pedagógico não mais intimista, preso ao mundo fechado da sociedade secreta, mas justamente ao ideal universalista da humanidade. (GIUBERTONI 1985: 63) ${ }^{12}$

Nesta vertente, a formação não se reduz ao universo fictício da personagem, mas abarca o horizonte de expectativa do leitor e, por extensão, de toda a humanidade. É a educação, a formação do homem nos princípios do humanismo que está por trás do Bildungsroman goethiano. Homem esse que, integrado à sociedade, é conduzido pelos princípios da tolerância religiosa, do ideal da igualdade, da fé no homem e na natureza e do culto à Humanidade.

12 "Ben lungi dall'assumere atteggiamenti antireligiosi, la massoneria tedesca si inserisce nel solco della tradizione mistica ed è pronta a far confluire in sé l'aura di intensa partecipazione delle cellule pietiste con gli ideali illuministici della tolleranza e dell'Humanität. Il punto di più intimo contatto e la diretta eredità che i massoni rilevano dai pietiste è proprio il Bildungsideal, che si carica ora di una valenza pedagogica non più intimisticamente rivolta al chiuso mondo delle conventicole ma esteso all'ideale universalistico dell'umanità." 
Esta pretensão de formação do novo homem, para a nova sociedade, para a modernidade, não se baseia em bruscas mudanças revolucionárias, mas em um processo lento e imperceptível ao homem comum. Quanto mais imperceptível for essa formação, mais eficaz e mais influente ela será. Goethe escreve de maneira significativamente velada o real e o misterioso processo de formação, de autodescoberta da personagem Wilhelm que, de maneira quase imperceptível, se torna grande defensor dos ideais do humanismo, os

iluministas da tolerância e da Humanidade. O ponto de maior contato íntimo e a herança direta que os maçons trazem dos pietistas é justamente o Bildungsideal, que se preocupa agora com um valor pedagógico não mais intimisticamente preso ao mundo fechado da sociedade secreta, mas justamente ao ideal universalista da humanidade. (GiUBERTONI 1985: 72) ${ }^{13}$

Portanto, aceitando-se esses pressupostos esotéricos, a falta de uma definição clara do conceito de Bildungsroman muito se deve ao fato de essa formação constituir uma forma contraditória e velada. Como expõe Giubertoni:

o Bildungsideal maçônico forma-se potencializando, no senso do mistério, a aura do segredo, já própria da educação pietista. Isso dará lugar a uma paidéia amnésica que absolve, ou pretende absolver, a problemática mediação entre sombra e luz, razão e mistério, sem anular nenhum dos elementos contrários, porque propriamente na polaridade ela encontra sua força formativa e plasmada. (GIUBERTONI 1985: 80) ${ }^{14}$

13 "L'autocoscienza raggiunta attraverso il misterio: questo il senso della Bildung massonica [...] Ma Wilhelm non sospetta neppure che sulla sua Bildung aleggi la mano massonica dell'Abate, di Jarno e di quanti altri membri della Società della Torre vorranno prendersi cura di lui. Egli è tenuto accuratamente all'oscuro dei retroscena che sottendono la sua formazione."

14 "Il Bildungsideal massonico si forma potenziando nel senso del misterio l'aura del segreto, già propria dell'educazione pietista. Ciò darà lugo ad una paideia anamnestica che assolve, o pretende di assolvere, la problematica mediazione tra l'ombra e la luce, tra la ragione e il mistero, senza annientare nessuno degli elementi contrari, perché proprio sulla polarità essa fonda la sua forza formativa e plasmante." 
Opondo-se à formação contemplativa interior da Bela Alma, Wilhelm é formado para o exterior, para a ação. Lukács afirma: "O momento de transição para a educação de Wilhelm Meister consiste precisamente no afastamento dessa pura interioridade (Bela Alma), que Goethe condena como vazia e abstrata, como também Hegel mais tarde em sua Fenomenologia do Espirito. É certo que essa crítica à canonista (Bela Alma) é levada a cabo por Goethe com acentos muito leves e sutis". (LuKÁCs 1994: 602) Isso se confirma na Carta de Aprendizado:

Longa é a arte, breve a vida, difícil o juízo, fugaz a ocasião. Agir é fácil, difícil é pensar; incômodo é agir de acordo com o pensamento. Todo começo é claro, os umbrais são o lugar da esperança. O jovem se assombra, a impressão o determina, ela aprende brincando, o sério o supreende. A imitação nos é inata, mas o que se deve imitar não é fácil de reconhecer. Raras as vezes em que se encontra o excelente, mais raro ainda aprecia-lo. Atraem-nos a altura, não os degraus; com os olhos fixos no pico caminhamos de bom grado pela planície. Só uma parte da arte pode ser ensinada, e o artista a necessita por inteiro [....] As palavras são boas, mas não são o melhor. $\mathrm{O}$ melhor não se manifesta pelas palavras. $\mathrm{O}$ espírito, pelo qual agimos, é o que há de mais elevado. Só o espírito compreende e representa a ação [...] O ensinamento do verdadeiro artista abre o espírito, pois onde faltam as palavras, fala a ação. $\mathrm{O}$ verdadeiro discípulo aprende a desenvolver do conhecido o desconhecido e aproxima-se do mestre. (GOETHE 1988: 496) ${ }^{15}$

15 "Die Kunst ist lang, das Leben kurz, das Urteil schwierig, die Gelegenheit flüchtig. Handeln ist leicht, Denken schwer; nach dem Gedanken handeln unbequem. Aller Anfang ist heiter, die Schwelle ist der Platz der Erwartung. Der Knabe staunt, der Eindruck bestimmt ihn, er lernt spielend, der Ernst überrascht ihn. Die Nachahmung ist uns angeboren, das Nachzuahmende wird nicht leicht erkannt. Selten wird das Treffliche gefunden, seltner geschätzt. Die Höhe reizt uns, nicht die Stufen; den Gipfel im Auge wandeln wir gerne auf der Ebene. Nur ein Teil der Kunst kann gelehrt werden, der Künstler braucht sie ganz [...] Die Worte sind gut, sie sind aber nicht das Beste. Das Beste wird nicht deutlich durch Worte. Der Geist, aus dem wir handeln, ist das Höchste. Die Handlung wird nur vom Geiste begriffen und wieder dargestellt. [...] Des echten Künstlers Lehre schliebt den Sinn auf; denn wo die Worte fehlen, spricht die Tat. Der echte Schüler lernt aus dem Bekannten das Unbekannte entwickeln und nähert sich dem Meister." 
Nesse sentido, o verdadeiro ensinamento não é autocontemplação, mas o agir no mundo. $\mathrm{O}$ artista é o homem da práxis, o agir na natureza e no mundo para a formação e o conhecimento de si mesmo e de toda a humanidade: "Segundo a concepção de Goethe, a personalidade humana só pode desenvolver-se agindo. Mas agir significa sempre uma interação ativa dos homens na sociedade”.(LukÁcs 1994: 600) E Helmut Thielicke argumenta que "o Eu enteléquico, portanto, jamais pode ser visado e descoberto diretamente. Ele só se dá a conhecer na sua relação com o exterior. Ele de certo modo 'é' essa relação”. (Thielicke 1993: 47) Portanto, o auto-conhecimento não se dá a partir do interior, mas do exterior.

A ação é que cria, recria e move o mundo e não a palavra. A mensagem humanista resume-se na idéia de que No princípio era a Ação e não o Verbo. Isso nos remete a uma concepção de mundo que não nega a materialidade, como a Bela Alma, mas que também não nega a espiritualidade como no panteísmo. Desta maneira, há uma hipótese de aproximação com a Weltanschaunng da Kabbala. Gershom Scholem, uma das maiores autoridades sobre essa doutrina judaica, explica que

todos os cabalistas concordam em que nenhum conhecimento religioso de Deus, mesmo do tipo mais elevado, pode ser obtido exceto através da contemplação do relacionamento de Deus com a criação. [...] Ein-Sof (infinito) é a perfeição absoluta na qual não há distinções nem diferenciações, e, de acordo com alguns, nem mesmo vontade. Não se revela de uma maneira que torne possível o conhecimento de sua natureza, e não é acessível nem mesmo ao mais profundo pensamento dos contemplativos. Apenas através da natureza finita de cada coisa existente, através da existência verdadeira da própria criação, é possível deduzir a existência do Ein-Sof como a primeira e infinita causa. (SCHOLEm 1989: 80)

Nessa presença e nessa ação da divindade espiritual presente na natureza material é que o homem adquire o verdadeiro conhecimento. "O próprio Goethe deve ter-se visto essencialmente como um pesquisador da natureza para quem a onipresença do divino na multiplicidade das formas finitas é o conteúdo adequado da fé." (Thielicke 1993: 111) 
Assim, o abade, logo depois da carta de aprendizado, diz para Wilhelm, o neófito finalmente formado: "Glória a ti, jovem! Chegaram ao fim teus anos de aprendizado: a Natureza te absolveu". (Goethe 1988: 497) ${ }^{16} \mathrm{O}$ aprendizado se encerra com a absolvição da Natureza, que tem esse poder por ser justamente a materialização da divindade. Não se trata de panteísmo, pois não há nunca a negação do espírito em detrimento da existência material. A divindade infinita se revela na criação, na natureza finita. A formação está completa, pois a divindade materializada na natureza o absolveu, porque agora ele já compreendeu que é através da ação do infinito na natureza finita, que o homem se reconhece como natureza finita onde habita a divindade infinita, ou seja, como emanação do Ein-Sof e, portanto, idêntico ao infinito. $\mathrm{O}$ homem e a humanidade como um todo se identifica ao infinito, ao absoluto. Esse é o princípio fundamental, mais profundo, do humanismo.

A tentativa de se provar que essas idéias pertencem ao Neoplatonismo, ao Gnosticismo, à Cabala, à Alquimia, ou qualquer outra forma de misticismo é absolutamente secundária, já que Goethe nunca deixou claro seu total comprometimento com uma ou outra doutrina. Contudo, o fundamental é compreender que na idéia de formação está presente a relação do "eu" com a natureza e com a divindade, que dialeticamente se diferenciam e se identificam, e que, alienado da sua essência mais profunda, só se autoidentifica através de sua formação no mundo e no conhecimento do infinito que desabrocha dentro de si: o divino no humano, ou seja, a divindade que se revela na humanidade em formação. Não se trata, entretanto, de panteísmo de inspiração em Spinoza, pois como esclarece Anatol Rosenfeld:

Spinoza viu as coisas individuais, os modi, dentro da unidade de Deus; Goethe viu Deus dentro da multiplicidade das coisas individuais. Aquele, parte da unidade divina e todos os fenômenos singulares nada são senão ondas passageiras no mar do infinito; este parte do fenômeno singular e descobre nele a essência divina. (ROSENFELD 2000: 261)

Assim, pode-se concluir que a grande riqueza e a grande profundidade desse romance de Goethe reside, justamente, nessa tentativa de concilia-

16 "Heil dir, junger Mann! Deine Lehrjahre sind vorüber; die Natur hat dich losgesprochen." 
ção ${ }^{17}$ entre espírito e matéria. Não se nega a busca da interioridade no processo de formação humanista, mas claramente se acentua a atividade do homem na sociedade, como sujeito da história: "Os seres humanos desse romance estão agrupados de um modo praticamente exclusivo em torno da luta pelo ideal do humanismo, em torno da questão dos dois extremos falsos: o sentimentalismo e o praticismo. Note-se, porém, como Goethe, começando por Lothario e Natalie, que representam uma superação dos falsos extremos, dispõe sua galeria de "praticistas", desde Jarno e Therese até Werner e Melina; como nessa série nenhum homem se assemelha ao outro e no entanto não se distinguem dos demais por meios pedantes, analítico-intelectuais, e como, ao mesmo tempo, se forma espontaneamente, sem palavras que a comentem, a hierarquia da significação humana, fundada na aproximação ao ideal humanista". (LuKÁcs 1994: 613)

\section{Novalis}

Contrariamente a personagem Wilhelm Meister, do romance de Goethe, o protagonista da narrativa de Novalis, Heinrich von Ofterdingen, tem uma formação baseada exclusivamente no conhecimento interior. Desta forma, em Novalis, Bildung não significa "formação" ou "instrução", mas o conhecimento de si mesmo através de iniciação nos mistérios do misticismo esotérico. A crítica de Novalis ao romance de Goethe se dá, sobretudo, porque, na obra do primeiro, a contemplação predomina sobre a ação e a revelação da divindade - e conseqüente identificação do finito com o infinito - é pelo caminho da poesia contemplativa e não da vida prática ativa: "Os homens de ação, que nasceram para as coisas do mundo, não podem, tão logo, contemplar-se e vivificar-se”. (Novalis 2001: 206) ${ }^{18}$ A grande crítica de Novalis ao romance de Goethe é que o primeiro propõe uma formação de tendência mística, ao contrário do segundo, que concede à ação a base fundamental da educação humanista.

17 Willi BoLLE, na página 10, de seu livro grandesertão.br mostra como Goethe, ao invés do confronto entre as oposições, propõe sempre o diálogo.

18 "Menschen, die zum Handeln, zur Geschäftigkeit geboren sind, können nicht früh genug alles selbst betrachten und beleben." 
Novalis claramente ataca Wilhelm Meisters Lehrjahre como sendo "seguramente, totalmente prosaico e moderno". (Novalis 2001: 544) ${ }^{19}$ Para ele, o grande erro de Goethe é desprezar o misticismo: "O romântico não aparece, nem a poesia da natureza, nem o maravilhoso - trata somente de coisas humanas, a natureza e o misticismo são totalmente ignorados". (Novalis 2001: 544) 20 Também não o perdoa pela ausência do fantástico, do maravilhoso e de certa religiosidade: "É uma história poeticamente caseira e burguesa. O maravilhoso é tratado como expressão da poesia e da exaltação. $\mathrm{O}$ ateísmo artístico é o espírito do livro. (Novalis 2001: 544) ${ }^{21}$ É um romance, enfim, para Novalis, muito mais preocupado com a vida prática do que a contemplativa: "Economia demais, com muitos prosaísmos, para atingir algum efeito poético." (Novalis 2001: $544)^{22}$ Em Heinrich von Ofterdingen não há propriamente ação, todo desenrolar da narrativa parte das reflexões, sonhos, visões e contemplações do protagonista. Não há uma série de aventuras e acontecimentos de interesse econômico, como acontece em Wilhelm Meisters Lehrjahre. Por isso, afirma Paola Mayer: "não é que o romance de Goethe não seja poético; pelo contrário, ele é reprovado por usar a Poesia para elevar a economia; seria o mesmo que dizer que a Poesia é feita para sua autodestruição". (MAYER 1999: 85)23

Em Heinrich von Ofterdingen a formação do homem se dá pela visão mística, sobrenatural, que o poeta-profeta recebe como iluminação direta da divindade. É através da poesia que o divino se revela ao homem e proporciona a revelação da unidade entre finito e infinito, o Um eterno. Essa fusão do absoluto no contingente é o enigma mais profundo que

19 "gewissermaßen durchaus prosaisch - und modern"

20 "Das Romantische geht darin zu Grunde - auch die Naturpoesie, das Wunderbare - er handelt bloß von gewöhnlichen menschlichen Dingen - die Natur und er Mystizism sind ganz vergessen."

21 "Es ist eine poetisierte bürgerliche und häusliche Geschichte. Das Wunderbare darin wird ausdrücklich, als Poesie und Schwärmerei, behandelt. Künstlerischer Atheismus ist der Geist des Buchs."

22 "Sehr viel Ökonomie - mit prosaischem, wohlfeilem Stoff ein poetischer Effekt erreicht."

23 "it is not that Goethe's novel is unpoetic; rather, it is reproached for using Poesie to elevate economics, which is to say that Poesie is made to self-destruct." 
reside na essência do amor, que une, através da poesia e da natureza, a parte ao todo:

Eins in allem und alles im Einen

Gottes Bild auf Kräutern und Steinen

Gottes Geist in Menschen und Tieren,

Dies mub man sich zu Gemüte führen.

Keine Ordnung mehr nach Raum und Zeit

Hier Zukunft in der Vergangenheit.

Der Liebe Reich ist aufgetan,

Die Fabel fängt zu spinnen an. (Novalis 2001: 260) 24 $^{24}$

Assim, a formação do homem é para o reino do amor, para a civilização do amor, onde o Eu se identifica com todos os seres como a própria divindade. O divino seria a essência numenal dos seres que ao se unirem identificam-se, dialeticamente, todos ao Todo e a si mesmo, a identidade aniquilada no eterno absoluto. Poesia e religião se identificam, pois a poesia é a revelação da divindade na natureza. Para

Novalis, a conversão à poesia e à religião é a mesma. [...] Böhme, em outras palavras, tornou possível a fusão entre a religião e a poesia, alcançada apenas por aqueles que entendem que a poesia reproduz a própria função de espelho da Natureza - espelho, no sentido de manifestação simbólica do divino". (MAYER 1999: 65) 25 $^{25}$

Como busca dessa revelação simbólica da divindade, Novalis faz o protagonista de seu romance inacabado buscar desde o início a misteriosa blaue

24 Tradução literal não poética: "Em todas as coisas o Um e o Um em todas as coisas. A imagem de Deus na relva e na pedra, o espírito de Deus nos homens e nos animais. Isto deve estar no coração do homem. Nenhuma ordem mais no espaço e no tempo. O futuro, aqui, no passado. Inicia-se o reino do amor, começa o tempo da fábula."

25 "Novalis, conversion to religion and to Poesie are one and the same. Böhme, in other words, made possible that fusion of religion and Poesie, reached only by those who understand that Poesie duplicates nature's own mirroring function mirror, that is, in the sense of symbolic manifestation of the divine." 
Blume . Esta flor, na verdade, é símbolo da divindade, da sabedoria, do amor. Conquistar a flor é conquistar o conhecimento da divindade humana. É o auto-descobrimento do divino no humano que o torna poeta e, portanto, divino. "Para Novalis a flor é o símbolo do amor e da harmonia que caracterizam a natureza primordial; a flor identifica-se ao simbolismo da infância e, de certo modo, ao do estado edênico".(Chevalier \& Gheerbrant 1996: 437) A escolha do azul não é aleatória. Dentro da perspectiva mística que Novalis quer iluminar em seu romance, o azul está claramente apropriado uma vez que

é a mais profunda das cores: nele, o olhar mergulha sem encontrar qualquer obstáculo, perdendo-se até o infinito. Imaterial em si mesmo, o azul desmaterializa tudo aquilo que dele se impregna. É o caminho do infinito, onde o real se transforma em imaginário. Entrar no azul é do espelho. (Chevalier \& GHeErbrant 1996: 107)

Compreende-se, assim, o encerramento da primeira parte do romance, em que o narrador nomeia Sofia (Sabedoria) como a sacerdotisa dos corações. A divindade, que se revela ao homem através da sabedoria poética, reside no coração do homem. Ela é o elemento divino na alma humana: "Sofia é a eterna sacerdotisa do coração". (Novalis 2001: 258)26 Paola Mayer lembra que

Sofia ou sabedoria divina é o elemento feminino, passivo da divindade. O espelho em que a vontade eterna (o Pai) vê a si mesmo e que projeta as imagens das coisas possíveis. No mundo criado, ela é o elemento divino na alma humana, a noiva eterna que Adão perdeu com sua queda. (MAYER 1999: 22) ${ }^{27}$

Assim, pode-se ver que as diferenças entre o Bildungsroman de Goethe e de Novalis são bastante evidentes no que tange a seu ponto fundamental: a

\footnotetext{
26 "Sophie ist ewig Priesterin der Herzen."

27 "Sophia or divine wisdom is the feminine, passive element of the divinity, the mirror in which the eternal will (the Father) sees itself and in which it projects the images of all possible things. In the created world, she is the divine element in the human soul, the heavenly bride whom Adam lost by his fall."
} 
orientação dada para a formação do sujeito e de toda humanidade. Enquanto Novalis visa a formação místico-contemplativa, Goethe visa a formação humanista intelectual que promova uma ação prático-social. Desta forma, Jürgen Jacobs e Markus Krause sugerem que no romance de Novalis, o estranhamento entre o sujeito e o mundo - uma característica própria do Bildungsroman - é superada devido à eliminação da identificação do sujeito com o mundo, do Eu com o todo: "Não é, pois, propriamente o problema central da Formação, o conflito da separação entre o sujeito e o mundo, eliminado com Novalis? Todavia, Ofterdingen nasce de uma profunda ruptura com o Wilhelm Meister goethiano.” (JACOBS \& KRAUSE 1989: 113) ${ }^{28}$

Goethe, com seu Wilhelm Meister, deixa em eterno devir a fusão dialética da reciprocidade entre sujeito-objeto e objeto-sujeito, porque sugere como perspectiva a realizar-se, em termos habermasianos, a união da filosofia da reflexão com a filosofia da práxis. Promoveria, assim, a fusão da idéia hegeliana do absoluto que toma consciência de si através da reflexão subjetiva interior com a filosofia da práxis marxista, voltada para a esfera da ação. Entre o caminho do conhecimento reflexivo e da ação se apresenta, como mediadora da formação, a Bildung, a formação humanista, que é o movimento em direção à transcendência, uma vez que a humanidade é vista como um todo e, cada indivíduo, parte integrante desse todo que tem como objetivo essa transcendência, esse estágio moral de educação idealizado por Lessing e Schiller.

O Bildungsroman seria, portanto, o meio pelo qual se expõe o eterno movimento de ida e volta da reflexão à ação, da ação à reflexão, que tornaria o homem consciente de si, como finito que se reconhece como absoluto, e consciente da vida como atividade. A formação seria o meio da realização da reflexão e da ação. Não se afirma a ação e se nega a reflexão, mas também não se nega a ação e se afirma a reflexão. Pelo contrário, afirma-se a síntese dialética da reflexão e da ação através do romance e não

28 "Denn ist nicht gerade der Kern des Bildungsproblems, die spannungsvolle Auseinandersetzung zwischen Subjekt und Welt, bei Novalis eliminiert? Immerhin entstand der Ofterdingen auf dem Hintergrund einer intensiven Auseinandersetzung mit dem Goetheschen Wilhelm Meister und gehört somit untrennbar zu dessen Wirkungsgeschichte." 
da filosofia, uma vez que a arte é o grande meio de realização da educação da humanidade. Wilhelm não é filósofo, mas sim o artista da reflexão e da ação.

\section{Referências bibliográficas}

Bolle, Willi. grandesertão.br. São Paulo, Duas Cidades / Editora 342004.

Chevalier, Jean \& Gheerbrant, Alain. Dicionário de Símbolos. 10ª ed. Rio de Janeiro, José Olympo 1996.

Filoramo, Giovanni. A History of Gnosticism. Oxford, Blackwell 1990.

Giubertoni, Anna. Le radici massoniche del Bildungsroman. In: Bertini, M. Autocoscienza e Autoinganno - Saggi sul romanzo de formazione. Napoli, Liguori Editore 1985.

Goethe, J. W. Wilhelm Meisters Lehrjahre. In: Werke. (Hamburger Ausgabe, Band VII). München, Deutscher Taschenbuch Verlag 1988.

Gray, Ronald D. Goethe the Alchemist. Cambridge, Cambridge U. P. 1952.

Jacobs, J. / Krause, M. Der Deutsche Bildungsroman. München, C. H. Beck 1989.

Joyce, James. Ulysses. London, Penguin 1992.

LukÁcs, Georg. A Teoria do Romance. Trad. José Marcos Mariani de Macedo. São Paulo, Livraria Duas Cidades / Editora 342000.

Lukács, Georg. Os Anos de Aprendizado de Wilhelm Meister. In: Goethe. Os Anos de Aprendizado de Wilhelm Meister (Apêndice). Trad. Nicolino S. Neto. São Paulo, Ensaio 1994.

Mans, Wilma Patricia. O Cânone Mínimo. São Paulo, Ed. Unesp 2000.

MAYER, Paola. Jena Romanticism and its Appropriation of Jakob Böhme. Montreal \& Kingston, McGill-Queen's University Press 1999.

MoretTi, Franco. Il Romanzo di Formazione. Torino, Einaudi 1999.

Novalis. Werke (brsg. u. komm. Gerhard Schulq). 4. ed. München, C. H. Beck 2001. 
O’Regan, Cyril. The Heterodox Hegel. New York, St. U. N. Y. Press 1994.

Rosenfeld, Anatol. Texto/Contexto II. São Paulo, Perspectiva 2000.

Scholem, Gershom. Cabala. Trad: Hinda Burlamaqui, Júlio César Guimarães

e Maria Lúcia W.P.Braga. Rio de Janeiro, A. Koogan 1989.

SchweIKLE, Günther u. Irmgard. Metzler Literatur Lexikon. Stuttgart, J.B.Metzler 1984.

Selbmann, Rolf. Der Deutsche Bildungsroman. $2^{\mathrm{a}}$ ed. Stuttgart, J.B.Metzler 1994.

ThieliCKe, Helmut. Goethe e o Cristianismo. Trad: Ronald Kyrmse. S.Paulo, Ars Poetica 1993. 